\title{
Peirce's Hypothesis of the Final Opinion
}

A Transcendental Feature and an Empirical Constraint

Aaron B. Wilson

\section{(2) OpenEdition \\ 1 Journals}

Electronic version

URL: http://journals.openedition.org/ejpap/1319

DOI: 10.4000/ejpap.1319

ISSN: 2036-4091

Publisher

Associazione Pragma

\section{Electronic reference}

Aaron B. Wilson, « Peirce's Hypothesis of the Final Opinion », European Journal of Pragmatism and American Philosophy [Online], X-2 | 2018, Online since 11 January 2019, connection on 19 April 2019. URL : http://journals.openedition.org/ejpap/1319; DOI : 10.4000/ejpap.1319

This text was automatically generated on 19 April 2019

\section{(c) $(1) \odot$}

Author retains copyright and grants the European Journal of Pragmatism and American Philosophy right of first publication with the work simultaneously licensed under a Creative Commons AttributionNonCommercial-NoDerivatives 4.0 International License. 


\title{
Peirce's Hypothesis of the Final Opinion
}

\author{
A Transcendental Feature and an Empirical Constraint
}

Aaron B. Wilson

\section{Empiricist and Transcendentalist Approaches to Peirce's Thought}

Charles S. Peirce makes some of his strongest commitments to a form of empiricism in the 1903 Harvard lectures, in which he argues that "all our knowledge rests on perceptual judgments" (CP5.142/EP2:204) and that "perceptual judgments are the first premises of all our reasoning" (CP5.116/EP2:191). I have argued (Wilson 2016) specifically that Peirce's mature architectonic - or the strands of it that begin to coalesce around 1902-1903 - is a particularly strong form of empiricism, in that it does not recognize any of our knowledge as a priori, or as indefeasible by the judgments of sense perception or by what can be correctly inferred therefrom. Even so-called analytic knowledge is not a priori, on Peirce's account, as he holds that necessary reasoning involves perception or perception-like states involving imagined diagrams. ${ }^{1}$ An inference from an imagined diagram involves an inference from a type of perceptual judgment. Long before the 1903 Harvard lectures, in his 1877 "The Fixation of Belief" (henceforth Fixation), he argues against the "a priori method" of fixing belief in both science and philosophy (W3: 254-6), claiming that its essence is "to think as one is inclined to think." Peirce specifically identifies Hegel as a proponent of the a priori method, and, in a footnote added in 1893, he also identifies Kant as one.

2 However, as it is well known, throughout his writings Peirce expresses his thought as having significant roots in Kantian philosophy. He also claims that his pragmaticism (as he calls it in 1904 and later) is closely allied to Hegelian absolute idealism - a claim that I will support in this essay. ${ }^{2}$ But whatever metaphysical ideas or elements he draws from transcendental idealism or from absolute idealism are stripped from any a priori epistemic foundation. For Peirce, strong empiricism is consistent with knowledge of 
metaphysical truths. As I have argued elsewhere, on his account, our sense perceptions represent instances of each of the three categories (Firsts, Seconds, and Thirds) including universals (or generals) and modal properties (such as conditional necessities), ${ }^{3}$ so that through inferential and prescissive processes we can distinguish objects or structures more general than what would fall within the purview of any special science. ${ }^{4}$ On his account, even highly speculative metaphysical theories can be regarded as, at worst, bad empirical theories; and all the great metaphysicians of the past, from Parmenides to Hegel, were really only drawing from experience, if only poorly. ${ }^{5}$

Contrary to Peirce, most metaphysicians have been under the impression that they have been drawing from a source of knowledge that is epistemically closed off from sense experience, and that their metaphysical claims are thereby safe from the revelations of ongoing sense experience. Such metaphysicians include Kant, and such metaphysical claims include his claims about the conditions for the possibility of empirical knowledge i.e., his transcendental idealism. Fully acknowledging Kant's positive influence on Peirce, the strong empiricist interpretation of Peirce resists the interpretation of him as a type of transcendental philosopher, so far as transcendental philosophy assumes a priori knowledge of the conditions for the possibility of empirical knowledge. ${ }^{6}$ It is not inconsistent with the claim that there is something like a transcendental condition for knowledge in Peirce's mature philosophy. Indeed, in this paper I will explain how there is.

As is well known, transcendental approaches to Peirce's thought gained prominence with the publication of Karl-Otto Apel's landmark work, Charles S. Peirce: From Pragmatism to Pragmaticism (1981). While at several places Apel acknowledges Peirce's movements away from and disagreements with Kant, especially during the final period of Peirce's thought (starting around 1898), Apel nonetheless argues that Peirce made a "semiotic transformation of Kantianism" (Appel, 1981: 191) that replaces the transcendental subject with an indefinite community of inquirers (ibid.: 193), and replaces a transcendental foundation for judgments of experience with a transcendental foundation for "the validity of the process of induction in the long run" (ibid.: 164-5). In Apel's view, Peirce effectively makes an a priori argument for the validity of induction by applying the pragmatic analysis of "real" as that which is cognizable in the long run. In "The Probability of Induction" (1878), Peirce argues that "that the rule of induction will hold good in the long run may be deduced from the principle that reality is only the object of the final opinion to which sufficient investigation would lead" (CP2.693/ W3:305). This certainly sounds like an a priori argument; and Apel is not alone in reading Peirce as making an a priori argument for the validity of induction. ${ }^{7}$

5 A systematic transcendental reading of Peirce has been most recently defended by Gabriele Gava, who argues that, in Peirce, an "ideal of rationality functions as a necessary but regulative (in Kant's sense) condition to account for semiotic processes" (Gava, 2014: 2), and that, for Peirce, purposefulness is a "necessary regulative condition of thinking" (ibid.). While necessary conditions do not entail transcendental conditions knowable only a priori, Gava's view is that, for Peirce, the purposefulness that directs semiotic processes, the esthetic ideal - which contains the final opinion or the logical ideal - is independent of experience in that it explains the semiotic process regardless of what experience might ever show. Gava is careful to distinguish between transcendental conditions as justificatory and as explanatory, and he argues that Peirce is only espousing the latter sort of transcendental condition. Nonetheless, this reading holds that, for Peirce, the 
transcendental conditions for semiosis cannot fail to explain semiosis as a result of any new experience or any new conclusion drawn logically from perceptual judgments.

As with other attempts to cast Peirce's philosophy as a type of transcendental philosophy,

${ }^{8}$ Gava's preserves Peirce's fallibilism. This is easy enough, since transcendental idealism, or virtually any claim to a priori knowledge, does not entail infallibilism. For whatever apriori-knowledge-generating-faculties are postulated, those faculties can be assumed fallible. ${ }^{9}$ However, as is evident from "Questions Concerning Certain Faculties Claimed for Man" (1868, henceforth Questions), Peirce is skeptical that we have any faculties other than (a) sense experience and (b) reasoning from sense experience, including abductive reasoning; and he seems particularly skeptical that we have the sort of faculties through which transcendental conditions of empirical knowledge have been presumed knowable. 10

7 I argue that Peirce does identify conditions for the possibility of knowledge, but that these conditions are not transcendental. They are empirical laws which determine that our opinions will tend to conform more and more to reality over an indefinite course of experience and inquiry. That is, Peirce's hypothesis of the Final Opinion may be regarded as, what Sacks (1997) calls, a "transcendental feature" of knowledge, which is a general condition for empirical knowledge, but where knowledge of that condition itself depends on the course of experience. The hypothesis of the Final Opinion, along with other hypotheses that coalesce with it and support it, are ultimately empirical hypotheses that are also transcendental features. Peirce recognizes that we need to explain how experience determines our minds to conform to reality. But he also recognizes that we can do so only through what we learn from experience.

Note, however, I will not specifically argue against other claims of transcendentalism in Peirce, such as claims concerning his universal categories (e.g., that Peirce treats their reality as a transcendental condition for the possibility of knowledge). ${ }^{11}$

While Peirce is engaged in a sort of "critique," in the Kantian sense of an examination of the general conditions for and limitations of knowledge, I am unsure whether or not empiricists such as Locke, Hume, and Reid could also count as "critical philosophers" in that sense, since they too identified general conditions for and limitations on knowledge. Locke's empiricist doctrine (that all our knowledge is built up from simple ideas of sense and reflection) and Hume's copy principle (that all ideas must be copied from sense impressions) are each a general condition for or limitation on knowledge. Though Peirce emphasizes that his own position on first principles, "critical common-sensism," has roots in Kantian critical philosophy, he regards critical common-sensism primarily as a variation of Reid's philosophy of common sense (CP5.439, 1905).

But the strong empiricist interpretation can grant that Peirce's philosophy has significant roots in and affinities with the idealist movement that Kant initiated. In fact, Peirce's philosophy may have more in common with Fichte's, Schelling's, and Hegel's systems than it does with Kant's. While it seems that each (Fichte, Schelling, Hegel) sought to establish a priori the conditions for the possibility of empirical knowledge, each also sought, as Peirce did, conditions that would not entail a ding an sich (a transcendental object or a wholly extra-empirical realm) or a transcendental subject with which those conditions are supposed to lie. Though Fichte seems to retain some notion of a transcendental subject, a self-positing "I" that is knowable by a type of intuition, this subject is not distinct from the self that is constrained by empirical law. ${ }^{12}$ Hegel also rejects Kant's separation of the subject from experience, ${ }^{13}$ and so does Schelling, each 
replacing the transcendental subject and the transcendental object with an "Absolute" in which the subject and object become unified. However, Schelling and Hegel also suppose (at least at certain stages) that the Absolute is knowable a priori by intellectual intuition. Peirce's early attack on such intellectual powers as intellectual intuition should be viewed as his earliest distinctive break with the German Idealist tradition, as well as his first significant commitment to some form of empiricism.

In the next section, I explain why Peirce draws the conclusion that there would be, with enough time and experience, a final conclusion to all inquiry. There are several auxiliary hypotheses underlying it, ranging from the belief-doubt model of inquiry to the hypothesis that natural laws are the result of evolutionary processes. In section three, I give a limited defense of Peirce's hypothesis of the Final Opinion. In section four, I explain how the Final Opinion is a condition for the possibility of knowledge but not a transcendental constraint on it. Here I invoke Sacks' (1997) distinction between transcendental constraints and transcendental features. While Peirce is not a transcendental philosopher in any rich sense, in the final section I explain how Peirce's metaphysics, particularly his hypothesis of the Final Opinion, is remarkably similar (to varying degrees) to the Absolute of the Absolute Idealists - Fichte, Schelling, and Hegel despite their apriorism.

\section{The Final Opinion as an Empirical Hypothesis}

Upon what does Peirce base his hypothesis that there would be, with enough time and experience, an ultimate conclusion that all inquirers would converge upon? As Daniel Herbert nicely puts it, "Peirce maintains that there is sufficient empirical evidence to support great confidence in the admittedly fallible hypothesis that the continuation of any given inquiry for a sufficient period of time would result in a final immovable consensus of opinion between the participants in that inquiry" (Herbert, 2015: 111). But exactly what, from experience, supports the theory that such a final consensus would eventually be reached? Herbert cites a passage from Peirce's 1885 review of Royce in which Peirce argues that a final opinion has already been reached on many specific questions, including ones that were previously thought unanswerable (EP1:234). However, skeptics of Peirce will argue that the fact that consensus has already been reached on a number of questions does not imply that an unshakable consensus would be reached on all meaningful questions.

It is well known that Peirce arrives at the analysis of truth as the Final Opinion, and at the analysis of the real as the object of that opinion, by applying his rule for attaining the third grade of clearness in our conceptions (i.e., the "pragmatic maxim"). It is also well known that this rule tells us to consider the sensible effects the object of the concept would have under different agential circumstances, as the wider function of concepts is to guide the conduct of the agent who possesses it. As Peirce explains with respect to the third grade analysis of the concept of force:

The idea which the word force excites in our minds has no other function than to affect our actions, and these actions can have no reference to force otherwise than through its effects. Consequently, if we know what the effects of force are, we are acquainted with every fact which is implied in saying that a force exists, and there is nothing more to know. (W3:270, 1878) 

third grade of clearness too nominalistic, and he will clarify that the object of a concept consists in the sensible effects the object (so conceived) would have under different sensible and practical circumstances. The object of a concept is conceived modally as a set or a system of habitual or dispositional properties, and not as a set of actual effects. What any object is, including what any "abstract object" is, is a collection or system of habits that are disposed to affect our experience and conduct.

15 Applying Peirce's pragmatic maxim to obtain an analysis of a concept involves broad reflection over our experience and knowledge, or, at least, over any experience or knowledge that we think might be relevant, even if indirectly, to the object of the concept and to our conduct about it. It involves formulating an empirical analysis of the object of the concept - specifically, an analysis that describes the object in terms of habits or dispositions to produce certain types of sensible effects under certain types of sensible circumstances. ${ }^{14}$ While Peirce seems to identify the pragmatic analysis with the concept itself - he says that "our conception of these effects is the whole of our conception of the object" (CP 5.402, my emphasis) - that analysis is most precisely a representation of the meaning of the concept. And, on Peirce's view, symbols (concepts being mental symbols) are meaningful only within a wider network of signs. No concept can be made very clear or useful to inquiry in isolation from many other concepts, especially concepts directly applicable to percepts. Note that because the application of Peirce's pragmatic maxim results in an empirical analysis, it involves abduction. Also note that, while Peirce does not deny that our concepts contain conventional elements, so far as it's interpreted with pragmatic clarity, a concept is subject to revision in the course of inquiry. As many scholars observe, on Peirce's view, meaning and knowledge develop together ${ }^{15}$

Thus, where Peirce comes to analyze truth as "the opinion which is fated to be ultimately agreed to by all who investigate" and reality as what is "represented in this opinion," he is neither defining a new conventional meaning nor is he identifying a transcendental condition for truth or knowledge. He is offering an empirical hypothesis that clarifies the concept of truth and the concept of reality. Truth is that representation which we would tend towards holding in the long run of experience, and reality is the object of that representation. Moreover, as Peirce explains later, reality itself draws us toward that Final Opinion.

But how does Peirce arrive at these specific hypotheses about truth and reality?

In "Some Consequences of Four Incapacities" (1868; henceforth Consequences), Peirce suggests that the distinction between the real and the unreal first occurs to us as an empirical discovery, when we discover that we have to correct ourselves. Thus, the concept of self-correction becomes tied to the concept of reality in its very inception:

[W] hat do we mean by the real? It is a conception which we must first have had when we discovered that there was an unreal, an illusion; that is, when we first corrected ourselves. Now the distinction for which alone this fact logically called, was between an ens relative to private inward determinations, to the negations belonging to idiosyncrasy, and an ens such as would stand in the long run. The real, then, is that which, sooner or later, information and reasoning would finally result in, and which is therefore independent of the vagaries of me and you. Thus, the very origin of the conception of reality shows that this conception essentially involves the notion of a COMMUNITY, without definite limits, and capable of a definite increase of knowledge. And so those two series of cognition - the real and the unreal - consist of those which, at a time sufficiently future, the community 
will always continue to re-affirm; and of those which, under the same conditions,

will ever after be denied. (CP 5.311)

Peirce claims that the fact that we sometimes have to correct ourselves "logically" calls for a distinction between "an ens relative to private inward determinations" and "an ens such as would stand in the long run" - i.e., between the unreal or the figment and the real as the final opinion. Of course, how the phenomenon of self-correction calls for this distinction in particular is not very transparent. Peirce's claim depends on certain other hypotheses developed in subsequent work.

One such other hypothesis is the well-known "belief-doubt theory of inquiry" that Peirce develops in Fixation and in other works. ${ }^{16}$ It does not itself prescribe methods of inquiry. It only describes the general psychological mechanics of inquiry. Surprise or failed expectation causes doubt in some belief, and the "irritation" of that doubt compels us to seek a belief that will satisfy that doubt - that is, until that belief gets disturbed by some further surprise or failed expectation. In Fixation, Peirce calls the struggle to escape doubt "inquiry," and he regards inquiry generally as a self-corrective process. ${ }^{17}$ An experience causes doubt in some belief, and the uneasiness of that state compels us to establish a new state of belief that puts the doubt to rest.

of course, self-correction and inquiry can come apart. With inquiry, the state of belief that eases doubt can be the same belief that was disturbed by doubt, such as when one experiences momentary doubt. But with self-correction, a different belief must be established and ease doubt, as "self-correction" implies that what was corrected was wrong and that the correction is correct. Now, with respect to what standard can a belief be correct or incorrect? Although it must introduce a normative dimension to inquiry, this standard needs to be intrinsic to the descriptive account. That is, it must have motivational force regardless of whether or not we intentionally adopt it, thus explaining why we would be inclined to adopt it intentionally. The standard must be the main source of our doubts. It must be external to our beliefs so that it can clash with them and cause doubt. Thereby, it must be something real, in the abstract sense of something that is independent of any representation of it.

It is crucial to distinguish how Peirce's normative claims are motivated by his descriptive account. The belief-doubt theory does not itself say that by nature we seek (or are compelled to seek) beliefs that correspond with reality. It only says that we naturally seek a state of belief that eases the irritation of doubt. But upon the further observation that only by seeking to conform our beliefs with reality will we most expediently overcome the threat of doubt, the claim that we should seek to conform our beliefs to reality acquires motivational force. As is well known, Peirce calls the method that seeks to have our beliefs fixed by external reality "the method of science" (5.384/W3:27). Other methods have us fix belief upon personal tenacity, social authority, or upon thought itself. While these methods might work in the short term, they will fail in the long run.

The method of science will most expediently deliver us from doubt because of the laws and mechanisms (or habits) through which reality affects our beliefs. Peirce thus adopts this further empirical thesis that real things "affect our senses according to regular laws" (ibid.). He conjectures:

[T] hough our sensations are as different as are our relations to the objects, yet, by taking advantage of the laws of perception, we can ascertain by reasoning how things really and truly are; and any man, if he have sufficient experience and he reason enough about it, will be led to the one True conclusion. (CP5.384/W3:27) 
The conjecture here is not just that real things affect our senses. It is that real things do so in ways that bring our beliefs in conformity with them over time. Later in his writings, Peirce even theorizes that there is a sort of attraction between reality and our minds that takes place through our senses, comparable to gravitational attraction. ${ }^{18} \mathrm{He}$ eventually surmises that the mind itself, in virtue of its outstanding ability to form new habits, ${ }^{19}$ is a self-correcting system. Although in the short term a variety of personal and social influences may compel us to hold false beliefs, even in the face of glaring counterevidence, in the long run those influences cannot withstand the overwhelming pressure of realty. Peirce remarks that even the most pigheaded of men "who has sworn by all the gods that he will never allow himself to believe the earth is round, and give him time enough, and cram that time with experience in the pertinent sphere, and he will surely come to and rest in the truth about the form of the earth" $\left(7.78\right.$, c.1905). ${ }^{20}$

Atkins (2017) points out that Peirce likely viewed the mind as a self-correcting system as early as Questions and Consequences, where he argues that mental action generally is of the nature of a valid inference (W2:214). If Peirce is correct there, then the mind would continuously self-correct and indefinitely approach the Final Opinion. But Atkins also points out passages in 1906 and 1911 suggesting that Peirce came to believe that the Final Opinion could only be reached or indefinitely approached if we adopt the right methods. ${ }^{21}$ In either case, the method of science ought to be adopted, if only because it would shorten the time it takes to reach the Final Opinion, more so than other methods (which might instead increase the time it would take, relative to the amount of time following no method at all).

The theory that anyone, with enough experience and reasoning, would eventually settle upon the conclusion that conforms to reality, where reality would no longer threaten to cause doubt, affords us our clearest notions of truth and reality - or so Peirce holds. The crucial point is that he seems to arrive at his theory upon several empirical considerations: (1) that generally we are compelled to correct ourselves; (2) that selfcorrection is most successful in the long run if we seek to have our beliefs fixed by external reality; (3) that there are laws of perception through which we are able to conform our beliefs to reality; and (4) that despite our various cognitive biases, over the long run, reality forces us, via laws of perception and cognition, to believe correctly. From these hypotheses he infers that the process of self-correction would indefinitely improve: gradually there would be fewer and fewer "surprises" that would occasion a need for self-correction.

\section{Objections to Peirce's Hypothesis of the Final Opinion}

All of the above empirical hypotheses, though I think they are plausible, are far from being established facts. In addition, there are other questionable premises in Peirce's reasoning to the conclusion that self-correction would tend toward a single final result, which concern why inquiry would not continue indefinitely in a linear fashion, or tend toward several different results. As Legg (2014: 210) explains:

Even if inquiry produces convergence in belief, why should it be to one, single endstate? That Peirce's account by definition forbids what might be called pluralistic convergence has been viewed as regrettably closed-minded. The charge has been pursued on a number of fronts: Quine in terms of his favoured ontological 
relativity: “[...] we have no reason to suppose that man's surface irritations even unto eternity admit of any one systematization that is scientifically better or simpler than all possible others" (Word and Object, 23), Hartry Field by imagining alien predication ("Realism and Relativism," 554), while Rorty presses the charge in terms of human cultural sensitivity (Contingency Irony and Solidarity).

In one respect, the objection of "pluralistic convergence" may be based on a misunderstanding of the Final Opinion and of Peirce's theory of signs in general. It does not matter what specific signs (or sign-vehicles) are used to represent real things. The forms by which the signs are interpreted also do not matter so much. What matters is that the signs and their interpretations allow the interpreters to anticipate and track real objects successfully, such that no further experience of that object could upset the interpretation or surprise the interpreter. While it seems impossible for two inconsistent theories to represent the same reality equally well, two theories can do so in such different ways that they might appear inconsistent.

It might seem that two genuinely inconsistent theories allow us to anticipate and track the same object equally well. But Peirce would object that even if they each appear to do so in the short term, differences will emerge in the long run (though, admittedly, the longer they prove pragmatistically equivalent, the greater reason we have to doubt Peirce's hypothesis). In another respect, pluralistic convergence might imply that reality itself is pluralistic, or that there are a plurality of realities, such that these realities can be inconsistent with one another. The hypothesis of plural and even inconsistent realities is one that Peirce simply does not find supported by experience. As I will explain further on, although he agrees that there is real plurality or variety, he also thinks that experience shows that variety tends toward uniformity.

Another objection is that, if there are an infinite number of realities to form beliefs about, then there are potentially an infinite number of beliefs to form and of self-corrections to take place. There might be a final result of inquiry on many specific questions; but if reality is infinite then there could not be a final result of inquiry in general. ${ }^{22}$ Peirce seems to assume that reality is not only a single system, but also a closed and finite system that would, in the long run, affect all inquirers in the same way. What, we might ask, supports this assumption?

31 First, note that a final result of inquiry in general only requires that reality is finite in distinct relations and qualities, and not in the number of individuals. There can be an infinity of real objects if those objects are qualitatively and relationally homogenous, since then it is not necessary to represent each one individually: one only has to represent the kind or type (by its qualities and relations) and that there are infinite members of that kind or type. ${ }^{23}$

However, this only hones in on the problem further. Why does Peirce assume that there is not an infinity of real and distinct qualities and relations?

It is not clear that we find an explanation for this until 1887-88, in "A Guess at the Riddle" ( $R$ 909/EP1:245-79), in which Peirce defends the metaphysical theses that "law is developed out of pure chance, irregularity, and indeterminacy" and that the universe is becoming more and more governed by laws. He argues that "we look back toward a point in the infinitely distant past when there was no law but mere indeterminacy; we look forward to a point in the infinitely distant future when there will be no indeterminacy or chance but a complete reign of law." (CP 1.409 / EP1:227). Peirce develops these ideas in his subsequent 1891-1893 Monist series, the first of which, "The Architecture of Theories" 
(1891), conjectures that "the only possible way of accounting for the laws of nature and for uniformity in general is to suppose them results of evolution" (CP 6.13 / EP1:288). ${ }^{24}$ While here Peirce might seem to make a transcendental argument, since he says the only possible way to account for laws and uniformity is via some evolutionary process, he is only overstating the strength of the evolutionary explanation. Peirce thinks that experience shows us that some evolutionary process best explains natural laws.

One empirical consideration that leads Peirce to the evolutionary hypothesis is that...

when we attempt to verify any physical law, we find our observations cannot be precisely satisfied by it, and rightly attribute the discrepancy to errors of observation, so we must suppose far more minute discrepancies to exist owning to the imperfect cogency of the law itself, to a certain swerving of the facts from any definite formula. (W8:101, 1891)

Peirce's prescience here is striking. As we now know, uncertainty is an inherent feature of subatomic laws. ${ }^{25} \mathrm{He}$ goes on to conjecture that biological and psychological laws also develop through evolutionary processes. At some places, he describes the process by which things come to be governed by laws as itself a law-governed process - i.e., a process governed by a law that he calls the law of habit (e.g. CP7.515). Here again, empirical considerations are what primarily lead him to hypothesize that there is such a primordial law. This is shown by an argument he makes earlier in the same essay:

[E]very person who wishes to form an opinion concerning fundamental problems should first of all make a complete survey of that human knowledge, should take note of all the valuable ideas in each branch of science, should observe in just what respect each has been successful and where it has failed, in order that, in the light of the thorough acquaintance so attained of the available materials for a philosophical theory and of the nature and strength of each, he may proceed to the study of what the problem of philosophy consists in, and of the proper way of solving it. (CP6.9/W8:85)

We should suppose that Peirce followed his own recommendation here and drew much, philosophically, from the different sciences.

Whether or not it is well supported by empirical evidence, Peirce's theory of the law of habit, that the universe is becoming more ordered and governed by law, explains why he would think that there is not an infinity of distinct qualities and relations, and that there is not a plurality of realities that can be inconsistent with one another. As order and lawfulness increases, variation decreases. Infinite variation is the opposite of order and lawfulness. It is chaos.

\section{The Final Opinion as a Transcendental Feature of Knowledge}

One might argue that Peirce is not committed to every real thing being an object of the Final Opinion. On the second grade of clearness, the real is conceived only as what is not dependent on any representation about it. ${ }^{26}$ And Peirce does not believe that a concept is meaningful only on the third grade of clearness, such that strictly first or second grade apprehensions of a concept are, separately from any third grade apprehension, completely vacuous. ${ }^{27}$ However, a mere first or second grade understanding of a concept is not as much use to inquiry as is a third grade grasp of the concept. We can meaningfully talk about reality simply as that which does not depend on any representation about it. But the concept of reality becomes particularly useful only when 
reality is conceived as dynamically related to perception and conduct. When so conceived, it is particularly and directly useful to the philosophical project of explaining how knowledge is even possible.

While Peirce denies the skeptical assumption that knowledge requires some form of absolute certainty, he belongs to the tradition that seeks to explain knowledge according to some metaphysical relation between the subject and the object of knowledge - a tradition that includes Kant and the German Idealists. Peirce's theory of the Final Opinion, and all the hypotheses that support or enter into it, is his explanation for how the subject and the object are metaphysically related (though in Peirce the subject is most properly conceived as the indefinite community of inquirers). The relation is this: the subject is necessarily determined to represent the object correctly in the indefinite long run, as a result of the subject's inherent ability to self-correct and the object's inherent ability to be represented by it.

This metaphysical explanation of the subject-object relation accounts very well for the fallibility of all inquiry: progress toward the Final Opinion is a very long-term trend, so that at any particular point inquirers can draw a false conclusion. But Peirce's theory also directly answers the question: upon what condition do we correctly represent the way things really are? His proposal is that a representation correctly represents the way things are when that representation would hold up over the long run of experience and inquiry (though it may be disturbed by doubt at various points). Observe that this is an external condition: whether a given representation has satisfied this condition is not introspectively knowable, or knowable a priori, as the Cartesian or the Kantian conditions for knowledge are supposed to be. It is not even clear that we would know that we have reached the Final Opinion when we have actually reached it. Plausibly we would, since whether we have reached the Final Opinion is itself a matter of fact or reality, and so would be correctly represented in the Final Opinion itself. ${ }^{28}$

41 An influential strain of recent Peirce scholarship does not view the tendency toward the Final Opinion as a metaphysical connection between the subject and the object of knowledge. Works by Hookway (2000, 2012), Misak (1991, 2007), Howat (2013, 2014), Legg (2014), and Atkin (2015) focus on Peirce's notion of the Final Opinion as a regulative assumption or an intellectual hope - which it certainly is - however, upon this strain, Peirce is not committed to the truth of the claim that there would be a final result of inquiry with enough time and experience, as he only thinks that we need to assume or hope that there would be such a final result, either in order to motivate inquiry or to make sense of it as a rational endeavor (or both). Passages such as the following are cited as evidence for this interpretation. Peirce writes to Lady Welby: "I do not say that it is infallibly true that there is any belief to which a person would come if he were to carry his inquiries far enough. I only say that that alone is what I call Truth" (SS 73, 1908). However, in this passage, Peirce is only expressing the fallibility of his theory of truth. It is fallible particularly because it is an empirical hypothesis. Although the hypothesis might not be best characterized as a belief, ${ }^{29}$ Peirce endorses it so far as he thinks it is acceptable to endorse any metaphysical hypothesis.

Peirce is not committed to the claim that there will be a Final Opinion. He acknowledges that all life could end long before it would be reached (e.g. CP 8.43, 1885). But he is as committed to the claim that there would be a final result of inquiry as he is to any other proposition in his philosophy. As a fallibilist and empiricist, he does not commit to any philosophical claim as anything more than a reasonable hypothesis that's subject to 
further inquiry. But the Final Opinion is a hypothesis to which he is fully committed as our most reasonable explanation for knowledge. Any attempt to portray Peirce's theory of truth as something other than a metaphysical theory would be, by his own lights, to make him out as a sort of nominalist. Although he is a strong empiricist, Peirce does not shy away from metaphysics, or from metaphysical theories of truth. ${ }^{30}$

Sometimes attending interpretations of the Final Opinion as a regulative assumption or intellectual hope is the identification of a type of transcendental argument or element in Peirce. The idea is that the regulative assumption or hope that all inquiry will converge on a final opinion is a necessary condition for any inquiry - albeit a necessary motivating condition that does not entail that the assumption or the hope is true. As Atkin (2015: 453) says, "the indispensability of some assumption for a practice proves nothing about the truth of that assumption." But it can be viewed as a transcendental element in the sense that the hope in or assumption of a final opinion is an indispensable condition for inquiry. Cooke (2005) goes further by arguing that this hope is not only a necessary motivational condition, but a necessary constitutive condition: what it means to inquire is, in part, to hope for an answer, even if one does not have sufficient evidence that an answer will be reached.

My approach recognizes a transcendental element in Peirce's account of truth and inquiry and, seemingly in contrast to the Misak-Hookway line of interpretation, an element that involves a commitment (albeit tentative) to the truth that there would be a Final Opinion with sufficient experience. But this transcendental element is not knowable a priori. It is only a transcendental feature of knowledge, as opposed to a transcendental constraint on knowledge. Sacks (1997) makes this distinction upon reflection on the later Wittgenstein, and he argues that Wittgenstein's notion of "language games" serve as transcendental features in his philosophy:

Roughly, a transcendental constraint indicates a dependence of empirical possibilities on a non-empirical structure, say, the structure of anything that can count as a mind. Such constraints will determine non-empirical limits of possible forms of experience. [...] A merely transcendental feature, on the other hand, is significantly weaker. Transcendental features indicate the limitations on what, at a time, can be envisaged as possible, and to which alternatives cannot be made intelligible as long as they retain their transcendental status. Given this reversed direction of determination it follows that while transcendental features indicate limitations on what can be envisaged, those limitations, in so far as they are determined by no more than empirical facts, can themselves change over time, and moreover can change in a way that is not subject to any constraints whatsoever. A transcendental feature is, to speak metaphorically, no more than a shadow of necessity cast by whatever practices are current. (Sacks, 1997: 178)

While a transcendental constraint is transcendent of all possible experience and determines the forms or limitations of experience, a transcendental feature is an empirical constraint on what is possible: it expresses only what we can currently envisage as possible. It does not transcend all possible experience, but is rather what we come to see as possible given our experience. It is "transcendental" only in the sense that it is the general structure to which any experience is currently expected to conform. But since we expect that future experience will conform to this general structure as a result of past experience, we have no basis on which to declare it impossible for any future experience to fail to conform to it.

Peirce's theory of the Final Opinion (and the theories of cognition, inquiry, and natural laws that surround it) specifies the primary empirical constraint on knowledge, or the 
primary transcendental feature of knowledge, as it describes a general structure that knowledge is reasonably expected to take. The use of "transcendental" here seems broadly consistent with Gava's (2014), where $\mathrm{X}$ is transcendental if $\mathrm{X}$ is necessary to some $\mathrm{Y}$; or $\mathrm{X}$ is essential to $\mathrm{Y}$. It is necessary to knowing that $P$ that $P$ would be accepted as part of the Final Opinion. But the metaphysical necessity here cannot be known a priori. Gava is correct that, in Peirce, we abstract "fundamental relational structures" from experience. But he does not adequately explain how Peirce accounts for our knowledge of these structures independently of experience. Prescission and abstraction from experience are types of inferences from experience (CP 4.463); and if those inferences from experience are the only grounds upon which we can know the inferred object, then our knowledge of that object depends on experience.

\section{Absolute Idealism and Intellectual Intuition}

So while there is indeed some similarity between Peirce's philosophy and transcendental idealism, it would be incorrect to assume that there are a priori elements to the former. There is a closer affinity between Peirce's philosophy and absolute idealism. ${ }^{31}$ Peirce could even be said to "empiricize" absolute idealism. One might also argue that, shortly following the publication of Kant's first Critique, German philosophy began shifting toward what may be described as a type of empirical method: phenomenology. And while phenomenology is better known as a method or style first employed by Hegel, it was arguably first employed by Fichte. Unfortunately, Fichte along with Schelling and Hegel still err in thinking that their conclusions are safe from on-going revelations of sense experience.

Fichte describes the conditions of experience in terms of the structure that presents itself qua a form of self-consciousness that he calls "intellectual intuition." He claims that experience is structured most fundamentally by an "ego" and a "non-ego", or an "other," where the ego continually engages in self-conscious activity and conscious activity toward a non-ego, and where a synthesis occurs between the two activities - what he describes as a "reciprocal causality" (Fichte, 1994: 281). This reciprocal causality appears to comprise a dynamical and teleological process. While the ego is finite and limited in its freedom with relation to the non-ego, the ego posits itself as an "absolute ego" - an unlimited ego or an ego of unlimited freedom. The ego strives to realize this unlimited or absolute freedom through its transactions with the non-ego, but it can ever only approach this absolute freedom. Fichte remarks that "man is to draw infinitely nearer to the in itself unattainable freedom" (ibid.: 92). Such absolute freedom is unattainable, according to him, as the absolute ego is only an idea or ideal - albeit one that is fundamental to the ego, more fundamental, it seems, than representation. As Adamson remarks, for Fichte "the essence of a conscious being is not representation or knowledge, but activity or freedom," although this activity incorporates representation or knowledge (Adamson, 1881: 179). The activity is directed upon an ideal, the limitless or absolute ego, forming an "infinite tendency" toward an "unattainable freedom."

Peirce mentions Fichte at few places ${ }^{32}$ though not with much affection. At one place he criticizes Fichte's system as an "idealistic nominalism" (CP4.551, 1905), the reasons for which I will not investigate here. But that accusation notwithstanding, the parallels between Fichte's and Peirce's systems are quite direct and significant, whether or not Peirce intentionally drew from Fichte or acknowledges these parallels. Not only does 
Fichte's "Absolute Ego" seem to correspond to Peirce's Final Opinion as an ideal toward which our practical activity (or at least our scientific activity) is directed and would draw closer to over time ${ }^{33}$ they correspond in each being an ultimate condition or explanation for knowledge in the respective author's system. Furthermore, Peirce's analysis of experience is very similar to Fichte's. Peirce describes experience as a "two-sided consciousness of an ego and non-ego" $(8.330,1904)$, where the non-ego resists and reacts against the ego $(8.266,1903)$ in a sense not unlike the one we find in Fichte. The ego is Firstness (freedom, spontaneity) while the non-ego introduces Secondness into our experience (Brute resistance, reaction). And their interactions with each other introduces Thirdness, a lawfulness by which our experience develops toward a certain end.

However, Fichte assumes a certain capacity of which Peirce is highly skeptical - a capacity for "intellectual intuition," which seems closest to what, in Questions, Peirce criticizes as "intuitive self-consciousness." Peirce does not deny that we are selfconscious, or that we have knowledge of the self. But he denies that this self-conscious knowledge is intuitive - i.e., not inferred or arising from other cognitions. But so far as this intuition is phenomenological and does not establish any a priori knowledge, there's little difference between Fichte and Peirce in how they arrive at the conclusion that experience involves an interaction between an ego and a non-ego. It is well known that Peirce himself engages in phenomenological reflection in his phaneroscopic investigations of fundamental categories. He also seems to engage in phenomenological reflection in his description of experience as a clash between an ego and non-ego (to which he also comes through psychological theory, or reasoning from experience). Unfortunately, Fichte seems committed to an a priori knowledge of the ego and its activity. While Fichte says that intellectual intuition of the ego cannot be separated from sensible intuition of the non-ego within experience ${ }^{34}$ he insists that intellectual intuition is a source of knowledge that is independent of sense experience, arguing that "intellectual intuition provides the only firm standpoint for any philosophy" (Fichte, 1994: 49-50). Yet, one might defend Fichtean intellectual intuition as little more than "reflection" or "introspection," which empiricists such as Locke (1689) have upheld as a type of experience.

51 Schelling's metaphysics also casts reality in a dynamic and teleological form, and also bears resemblance to Peirce's own dynamic and teleological semeiotic and metaphysics. Schelling treats nature as mind-like or purposive, developing from an unconscious materiality, to organic forms, to conscious beings organized socially, to an Absolute consciousness in which, in his Identitätphilosophie, the subject and object of knowledge are identical. One correspondence between Peirce and Schelling that particularly stands out is between Peirce's "objective idealism" - the thesis that "matter is effete mind" and Schelling's view that "the laws of mind materialize into the laws of nature, or the formal annexes the material" (1978/1800: 14). Peirce acknowledges this correspondence between his and Schelling's philosophy:

I have begun by showing that tychism must give birth to an evolutionary cosmology, in which all the regularities of nature and of mind are regarded as products of growth, and to a Schelling-fashioned idealism which holds matter to be mere specialized and partially deadened mind. $(6.102,1892)$

While Peirce does not share Schelling's seemingly monistic view of the Absolute, he shares, at least in the 1891-93 Monist series, Schelling's attempt to subsume the material world into a world of purpose and representation. Commentators have taken particular notice of this. Dea (2015a) argues that Peirce's idealism falls in the absolutist camp, as 
opposed to James's pluralistic version of idealism, mostly due to Peirce's objective idealism. And Dilworth points out that Peirce's idealism is Schellingian particularly because Peirce "forged a theoretical explanation of how mind turns into matter, not how, in a chance world, matter turns into mind" (Dilworth, 2016: 262).

But a significant strain of apriorism seems more evident in Schelling than in Fichte. On Schelling's account, knowledge of the Absolute, or of the mental and developmental structure of reality, comes strictly by means of intellectual intuition. Sharply distinguishing intellectual intuition from sensible intuition, Schelling declares that "Intellectual intuition is the organ of all transcendental thinking" (1978: 27). Intellectual intuition has the Self or the subjective as its object, and from that intuition of the subjective conditions of experience we can arrive at a priori knowledge of the Absolute. Schelling also seems to identify intellectual intuition with the Self itself, making itself unconditioned by any previous cognition (ibid.). It is precisely this sort of intuition immediate cognition of the self not determined by any previous cognition - that Peirce rejects in both Questions and Consequences.

54 I will not comment much on the affinities between Peirce and Hegel, as these are better known and as many of the same general points concerning Fichte and Schelling apply to Hegel. While Peirce agrees with Hegel that reality has a rational, purposive, or quasimental structure, which develops towards something like an "Absolute," Peirce does not think, as Hegel appears to, that any of this can be known a priori. Recall that Peirce accuses Hegel in particular of following the a priori method, which is tied to another wellknown criticism, that Hegel denies the reality of the first two categories, in particular Secondness. In his 1885 review of Royce, Peirce famously complains of Hegel: "The capital error of Hegel which permeates his whole system in every part of it is that he almost altogether ignores the Outward Clash" (CP 8.41). By the "outward clash" Peirce means the confrontation with external reality that we experience through sense perception.

But Peirce agrees with Hegel and Schelling, against Kant, that the conditions for the possibility of empirical knowledge do not lie with a subject understood as distinct from the object-in-itself. Instead, they lie with a dynamical, teleological union between the subject and the object. Yet, while there are clear parallels between the Absolute of the German Idealists and Peirce's Final Opinion (or Final Interpretant), the German Absolute is a transcendental constraint knowable a priori, while the Final Opinion or Final Interpretant is only a transcendental feature. The Final Opinion explains the objectivity of our experience. But it is also a hypothesis or an abduction from experience. There are no special abilities, like "intellectual intuition," by which we can know a priori that experience and inquiry would eventually result in a fixed and final conclusion about the world, or in a fixed and final interpretation of any given sign. Moreover, in Peirce, unlike in Hegel and in Schelling, the teleological process through the subject and object of knowledge are necessarily related is not be understood as an entirely mental or rational process. Peirce is clear that external reality, and our experience of external reality, involves a brute or non-rational element, and that this non-rational (and non-mental) element also drives the process leading toward the Final Opinion.

Apel is correct that Peirce's philosophy involves a sort of synthesis of English and German philosophies (Appel, 1981: 20). Peirce purges nominalism from British empiricism and Scottish common-sensism, and combines empiricism and common-sensism with metaphysical theories that reflect those Hegel and Schelling more than they do those of Locke, Hume, or Reid. From a different angle, one can say that Peirce purges apriorism 
from German Idealism and combines it with epistemological and methodological principles that are more similar to those of Locke, Hume or Reid than to those of Kant, Schelling, or Hegel. The result is a system that might repulse proponents of both camps, but might nonetheless itself be a significant advancement toward that Final Opinion.

\section{BIBLIOGRAPHY}

ADAMSON Robert, (1881), Fichte, University of Wisconsin, Madison, J. B. Lippincott.

APPEL Karl-Otto, (1981), Charles S. Peirce: From Pragmatism to Pragmaticism, Amhert, MA, University of Massachusetts Press.

ATKIN Albert, (2015), "Intellectual Hope as Convenient Friction," Transactions of the Charles S. Peirce Society, 51 (4), 444-62.

ATKIN Richard K., (2016), Peirce and the Conduct of Life: Sentiment and Instinct in Ethics and Religion, Cambridge, UK, Cambridge University Press.

ATKIN Richard K., (2017), "Peirce on Truth as the Predestinate Opinion," European Journal of Philosophy, 26 (1), 411-29.

COOKE Elizabeth, (2005), "Transcendental Hope: Peirce, Hookway, and Pihlström on the Conditions for Inquiry," Transactions of the Charles S. Peirce Society, 41 (3), 651-74.

DEA Shannon, (2015a), “A House at War Against Itself: Absolute Versus Pluralistic Idealism in Spinoza, Peirce, James and Royce," British Journal for the History of Philosophy, 23 (4), 710-31.

DEA Shannon, (2015b), "Meaning, Inquiry, and the Rule of Reason: A Hookwayesque Colligation," Transactions of the Charles S. Peirce Society, 51 (4), 401-18.

DILWORTH David, (2016), "Peirce's Transmutation of Schelling's Philosophie der Natur," Cognitio, 17 (2), 253-90.

FICHTE J. G., (1994 [1797-1800]), Introductions to the Wissenschaftslehre and Other Writings, transl. and ed. by Breazeale D., Indianapolis, IN, Hacket Publishing.

GAVA Gabriele, (2014), Peirce's Account of Purposefulness: A Kantian Perspective, New York, NY, Routledge.

GILADI Paul, (2014), “Hegel's Critique of Kant's Transcendental Subject," in Burwood S., Felges T. \& Gray J. (eds.), Subjectivity and the Social World: A Collection of Essays Around Issues Relating to the Subject, the Body and Others, New Castle upon Tyne, Cambridge Scholars Publishing, 9-23.

HAACK Susan, (2007), “The Legitimacy of Metaphysics: Kant's Legacy to Peirce, and Peirce's to Philosophy Today," Polish Journal of Philosophy, 1 (1), 29-43.

HAACK Susan, (2009), "The Growth of Meaning and the Limits of Formalism: In Science, In Law," Analisis Filosofico, 29 (1), 5-29.

HARTSHORNE Charles, (1973), "Charles Peirce and Quantum Mechanics," Transactions of the Charles S. Peirce Society, 9 (4), 191-201. 
HERBERT Daniel, (2015), “Peirce and the Final Opinion: Against Appel's Interpretation of the Categories," in Gava G. \& Stern R. (eds.), Pragmatism, Kant, and Transcendental Philosophy, New York, NY, Routledge, 94-113.

HоокWAY Christopher, (2000), Truth, Rationality, and Pragmatism: Themes from Peirce, Oxford, UK, Oxford University Press.

ноокWAy Christopher, (2012), The Pragmatic Maxim: Essays on Peirce and Pragmatism, Oxford, Oxford University Press.

HOWAT Andrew, (2013), "Regulative Assumptions, Hinge Propositions and the Peircean Conception of Truth," Erkenntnis, 78 (2), 451-68.

Howat Andrew, (2014), “Prospects for Peircean Truth," Canadian Journal of Philosophy, 44 (3-4), $365-87$.

LEGG Catherine, (2014), “Charles Peirce's Limit Concept of Truth,” Philosophy Compass, 9 (3), 204-13.

MigotTI Mark, (2005), “The Key to Peirce's View of the Role of Belief in Scientific Inquiry," Cognitio , $6(1), 43-55$.

MISAK Cheryl, (1991), Truth and the End of Inquiry: A Peircean Account of Truth, Oxford, Clarendon Press.

MISAK Cheryl, (2007), "Pragmatism and Deflationism," in Misak C. (ed.), New Pragmatists, Oxford, Clarendon Press.

PEIRCE Charles S., (1931-1958) The Collected Papers of Charles Sanders Peirce, 8 vols., Hartshorne C., Weiss P., \& Burks A. W. (eds.), Cambridge, MA, Harvard University Press. (CP)

PEIRCE Charles S., (1967, 1971), The Charles S. Peirce Papers, Houghton Library, Harvard University. References are to the system of categorization in R. S. Robin, The Annotated Catalogue of the Charles S. Peirce Papers, and R. S. Robin, The Peirce Papers: A Supplementary Catalogue. (R).

PEIRCE Charles S., (1977), Semiotic and Significs: The Correspondence between C. S. Peirce and Victoria Lady Welby, Hardwick C. S. (ed.), Bloomington, IN, Indiana University Press. (SS).

PEIRCE Charles S., (1982, 1984, 1986, 1989, 1993, 2000, 2010), Writings of Charles S. Peirce: A Chronological Edition, 8 vols., Peirce Edition Project (eds.), Bloomington, IN, Indiana University Press. (W).

PEIRCE Charles S., (1992, 1998), The Essential Peirce, 2 vols., Houser N., Kloesel C. and the Peirce Edition Project, Bloomington, IN, Indiana University Press. (EP).

PEIRCE Charles S., (1993), Reasoning and the Logic of Things: The Cambridge Conference Lectures of 1898, ed. by Ketner K. L., \& Putnam H., Cambridge, MA, Harvard University Press. (RLT).

SACKS Mark, (1997), “Transcendental Constraints and Transcendental Features," International Journal of Philosophical Studies, 5 (2), 164-86.

SCHELLING F. W. J., (1978 [1800]), System of Transcendental Idealism, transl. by Heath P., Charlottesville, VA, University Press of Virginia.

SKAGESTAD Peter, (1981), The Road of Inquiry: Charles Peirce's Pragmatic Realism, New York, Columbia University Press.

WestPHAL Kenneth R., (2003), "Can Pragmatic Realists Argue Transcendentally?," in Shook J. (ed.), Pragmatic Naturalism and Realism, New York, NY, Prometheus Books, 151-75. 
WILSON Aaron B., (2012), "The Perception of Generals," Transactions of the Charles S. Peirce Society, 48 (2), 169-90.

WILSON Aaron B., (2016), Peirce's Empiricism: Its Roots and Its Originality, Lanham, MD, Lexington.

WILson Aaron B., (2017), “What Do We Perceive: How Peirce 'Expands Our Perception', in Hull K. \& Atkins R. K. (eds.), Peirce on Perception and Reasoning: From Icons to Logic, New York, NY, Routledge, 1-14.

\section{NOTES}

1. See Wilson (2016: 219-23).

2. In the full passage, Peirce explains that pragmaticism and Hegel's absolute idealism come apart with the pragmaticist's "vigorous denial that the third category (which Hegel degrades to a mere stage of thinking) suffices to make the world, or is even so much as self-sufficient" (CP5.436, 1904).

3. Wilson 2012, 2017.

4. As Peirce says, "metaphysics, even bad metaphysics, really rests on observations, whether consciously or not; and the only reason that this is not universally recognized is that it rests upon kinds of phenomena with which every man's experience is so saturated that ususally pays no particular attention to them" (CP6.2, 1898).

5. See CP7.579, 1867; CP8.37, 1871; CP7.485 1898; CP2.203, 1901; and CP1.129, 1905.

6. I use "empirical knowledge" to include perceptual knowledge, or proposition represented via a strictly perceptual process, indexed directly to percepts, and theories that are supported inferentially upon perceptual knowledge.

7. The best discussion I have seen concerning whether Peirce defends induction on a priori grounds is in Skagestad 1981.

8. For instance, Westphal 2003 and Cooke 2005.

9. Resistance to the a priori mode of thinking is, fundamentally for Peirce, resistance to a way of blocking inquiry and a commitment to fallibilism. While apriorists can be fallibilists, their commitment to fallibilism cannot go much further than a recognition that their claims could be in error. The infallibilist element of the a priori method is that it takes its a priori claims to be immune from doubt triggered by perception or what we can infer from perception.

10. In Questions, Peirce claims: "all our conceptions are obtained by abstractions and combinations of cognitions first occurring in judgments of experience" (W2:208, 1868).

11. Herbert 2015 makes arguments against claims that Peirce's universal categories (Firstness, Secondness, and Thirdness. In Wilson 2016, I argue that Peirce defends the reality of the categories based primarily on his logic and semeiotic, which he conceives as empirical inquiries (288-9).

12. One could read Fichte as a type of empiricist, so far as he declares that "all being is necessarily sensible being" (472/225).

13. On this point about Hegel, see Giladi 2014.

14. While some of these habits or dispositions might be conceived as intrinsic to the object and, therefore, central to the concept, others might be conceived as extrinsic or obtaining only in relation to a wider system. But any habit attributed to the object must have some ability to affect and be represented through sense perception and conduct, in order to add our grasp and use of the concept.

15. For instance, Haack 2009 and Dea 2015b

16. For instance, the 1903 Harvard Lectures; in particular, see CP5.50-51/EP2:153-4. 
17. Peirce describes science, common-sense, reasoning, and inquiry as subject to a process of self-correction, remarking that "inquiry of every type, fully carried out, has the vital power of self-correction and growth" (CP 5.583).

18. Peirce does so at least at two places: (1) "There is, then, to every question a true answer, a final conclusion, to which the opinion of every man is constantly gravitating. He may for a time recede from it, but give him more experience and time for consideration, and he will finally approach it" (CP 8.12, 1871). (2) "There is nothing extraordinary therefore in saying that the existence of external realities depends upon the fact, that opinion will finally settle in the belief in them. And yet that these realities existed before the belief took rise, and were even the cause of that belief , just as the force of gravity is the cause of the falling of the inkstand - although the force of gravity consists merely in the fact that the inkstand and other objects will fall" (CP 7.344, 1873).

19. See, for instance, CP 7.367 and CP 7.515.

20. More fully, Peirce writes: "Sooner or later [science] will attain the truth, nothing more. It means that if you take the most pigheaded and passionate of men who has sworn by all the gods that he will never allow himself to believe the earth is round, and give him time enough, and cram that time with experience in the pertinent sphere, and he will surely come to and rest in the truth about the form of the earth" (CP7.78, c.1905).

21. The passages are as follows: "if we can find out the right method of thinking and can follow it out, - the right method of transforming signs, - then truth can be nothing more nor less than the last result to which the following out of this method would ultimately carry us" (EP2:380). In 1911, he states, "I call[ed] 'truth' the predestinate opinion, by which I ought to have meant that which would ultimately prevail if investigation were carried sufficiently far in that particular direction" (EP2:457).

22. Peirce himself suggests that, even if a certain question would eventually be answered, several new questions may arise with each question that does get answered. In that case, it seems, we would never so much as even approach a final result of all inquiry. Peirce recognizes this a genuine possibility, but he does not believe that we have as much reason to accept this possibility as we do the alternative. He argues: "The problem whether a given question will ever get answered or not is not so simple; the number of questions asked is constantly increasing, and the capacity for answering them is also on the increase. If the rate of the latter increase is greater than that of the [former] the probability is unity that any given question will be answered; otherwise the probability is zero. Considerations too long to be explained here lead me to think that the former state of things is the actual one. In that case, there is but an infinitesimal proportion of questions which do not get answered, although the multitude of unanswered questions is forever on the increase" $(8.43,1885)$. Also see CP5.409 and EP2:457.

23. For example, "there exists three apples" represents precisely the same facts as "there exists an apple, there exists a second apple, and there exists a third apple" so long as the ordinal number is arbitrarily assigned and does not represent a particular position or relation among the individual members.

24. Elsewhere Peirce characterizes the movement "from difformity to uniformity" as the "law of habit" $(6.101,1902)$.

25. For more on the connections between Peirce's metaphysical hypotheses and quantum physics, see, for instance, Hartshorne 1973.

26. As Peirce puts it in "How to Make Our Ideas Clear," the real is "that whose characters are independent of what anybody may think them to be" (CP5.405/W3:271).

27. Originally, Peirce may have thought that the third grade analysis of a concept is the only genuine expression of a concept. But even if he had, he later gave that notion up. As he remarks to Paul Carus in 1903: "I ought to say that my three grades of clearness are not, as I seemed then 
to think, such that either the first or the second are superseded by the third, although we may say that they are acquired, mostly, in the order of those numbers" (CP8.218).

28. See Wilson (2016: 256-7). We might also worry about an infinite regression of knowledge claims: S knows that X, S knows that she knows X, S knows that she knows that she knows X, ad infinitum.

29. Peirce famously denies that belief has any place in science in the first of his 1898 Cambridge Conference lectures: "what is properly and usually called belief [...] has no place in science at all" (CP1.635/RLT 112). For enlightening analysis of this claim, see Migotti 2005 and Atkins 2016.

30. Haack nicely explains how Peirce's approach to metaphysics is empirical and distinct from Kant's: "Kant assumes that metaphysics is distinguished from physics precisely by virtue of 'lying beyond experience' (PM, p. 15). Metaphysics will be an a priori investigation of the conditions of the possibility of human knowledge; and thus will stand 'wholly isolated' (PM, p. 11). But Peirce's scientific metaphysics will be an a posteriori discipline, and anything but isolated. It will be continuous with the special sciences; but it is charged with investigating those aspects of reality too general to fall within their scope[.]" (Haack, 2007: 33).

31. Some might prefer "objective idealism" as the contrast to "transcendental idealism" within the German tradition. But a notion of an absolute or "unconditioned" plays a vital role in each Fichte's, Schelling's, and Hegel's philosophies, and those are the notions I find most similar to Peirce's notion of the Final Opinion.

32. At least among Peirce's works published in the Collected Papers; I have not sufficiently searched for references to Fichte in works not published in that collection.

33. Two comments: First, whether the Final Opinion, like Fichte's Absolute Ego, is an unattainable ideal is subject to interpretative dispute. On my reading, the Final Opinion is not unattainable. Perhaps the reason Peirce calls Fichte an idealistic nominalistic is precisely because Fichte sees the Absolute as unattainable. Second, the Fichtean Absolute Ego may correspond more precisely to the Peircean Summum Bonum, or the ultimate end of all action, is tied up with the Final Opinion, but is not it's a representation (or not necessarily a representation). Fichte's Absolute Ego is a state of absolute freedom, and that would more closely parallel Peirce's Summum Bonum than his Final Opinion.

34. In Introductions to the Wissenschaftslehre, Fichte (1994: 47) writes that "intellectual intuition is always conjoined with some sensory intuition."

\section{ABSTRACTS}

Idealist and Strong Empiricist approaches to Peirce's thought are irreconcilable so far as an Idealist interpretation commits Peirce to some form of a priori knowledge, particularly a priori knowledge of the conditions of empirical knowledge. However, while I favor the strong empiricist approach, I agree that there is something like a "condition for the possibility of empirical knowledge" in Peirce, and that this lies with his famous conjecture that, with enough time and experience, there would be a "final result" of all inquiry - "the Final Opinion." Though some argue that this is mainly a regulative assumption or intellectual hope in Peirce, I contend that he is committed to it as an empirical hypothesis which we should provisionally accept. As an empirical hypothesis, it is not a transcendental constraint on knowledge, though it can be considered a transcendental feature (following Sacks' (1997) distinction). That is, the thesis explains how knowledge is possible, but the epistemic status of the thesis itself is dependent on 
the course of experience. Here I explain how it is an empirical thesis and I explain the empirical considerations Peirce thinks support it. Though Peirce should not be considered a transcendental idealist in any robust sense, I give reasons for why he could still be considered a sort of absolute idealist.

\section{AUTHOR}

AARON B. WILSON

South Texas College

awilson3[at]southtexascollege.edu 